\title{
ROLEPLAY: THREE QUESTIONS AND ANSWERS
}

\section{Suzanne Larocque}

Recently, many educators have come to realize the importance of making second language learning enjoyable. It has also become clear that designing activities that will allow students to use the target language in meaningful situations is paramount. Meaningful use of the target language can take place when students are involved in problem solving activities, information gap games, peer teaching, roleplays and many other types of communicative activities that respond directly to their needs and interests. However, when I considered roleplay as a possible classroom activity three questions came to mind. Specifically, I wondered how to select and design roleplay situations appropriate for my students, how to prepare my students for these roleplay activities and how much control is necessary during this type activity. I felt that I had to answer these questions before using roleplay activities regularly with my second language students.

\section{How do I select or design roleplay situations appropriate for my students?}

Underlying one very popular interpretation of the communicative approach is the belief that speech acts are organized with a function in view, that is, in a given situation there is an attempt to accomplish something with or through language. Since the number of possible communicative functions is formidable, it is useful to divide them into more manageable units. Finocchiaro (1983) suggests five categories: personal, interpersonal, directive, referential, and imaginative. Each category contains specific functions. For example, in the category labelled personal, one finds functions which include expressing one's thoughts about topics such as happiness, fear, fatigue, doubt and love. Thus, the first step in organizing a roleplay activity is to determine which language functions to focus on. Then, the teachers must think of real life situations when these functions are used by native speakers. To better describe each proposed roleplay situation, it will be useful to use van Ek's four categories (1976) which include social roles, psychological roles, setting and surroundings.

Social roles deal with occupations and relationships, such as friend, official, or neighbour. Psychological roles deal with the degree of involvement, such as neutral or sympathetic. Setting involves both the geographic location and place, which could be a specific place indoors or outdoors and surroundings encompass all the human contacts involved.

Once the specific function and corresponding situations have been narrowed down, the next step is to look at the language involved. Naturally only the most predictable and typical expressions can be selected for 
inclusion in preparatory activities since it is almost never possible to identify exactly what will be said in a particular situation.

Now, what about the students? What if they don't want to role play receiving visitors from Italy at Dorval airport? Remember that the needs and interests of the students are of great importance and must be taken into account when defining roleplay situations. As Livingstone (1983) points out, role playing activities cannot be successful unless the students' level, needs, interests, and experiences are considered.

\section{How do I prepare my students for roleplay activities?}

Once decisions have made regarding the communicative function, the situation and the language appropriate to the situation, further preparation is still necessary. Livingstone (1983) discusses the linguistic, situational, cultural and factual phases involved in the preparation of roleplay activities. Linguistic preparation involves an accurate assessment of what language students will need. Situational and cultural preparation involves an assessment of the appropriateness of each roleplay activity and the students' readiness to deal with it. Neglecting this phase of preparation can lead to embarrassment, as it did in one of my classes. In this particular case, to introduce the roleplay activity I used a family tree with pictures showing the various members of a family and their relationship to each other. When the students were asked to repeat "This is my father, this is my mother," several of them began to giggle. It was only after several minutes and by the time most of the students were laughing that I realized why the exercise was having such an effect on my students. The people in the family tree I had prepared were all white whereas 90 percent of my students were black.

The third type of preparation is factual. For example, to prepare students to participate in a role play involving a tourist asking for directions in Montreal, both students and teacher should brainstorm on the names of the major tourist attractions in Montreal and how to get there. Once all the material necessary for a roleplay has been presented it's a good idea for the teacher to describe the general situation and explain the roles of both the players and the audience (Chesler, 1966).

It is important for the students to know what the situation is. If they don't, it should be intentional on the part of the teacher. For example, you might want the students themselves to identify the major conflict. But it is advisable to provide the students with as much information as possible about a role. It not only gives them a clearer picture of what to do but can make a not-so-pleasant role more attractive. By being immersed in a role, the students will feel that it is not themselves but the character they portray that is being cast in a bad light. To avoid negative reactions a student should be free to decline to participate. Letting students volunteer 
for roles is more conducive to success, especially if the students are not familiar with roleplay activities.

Roleplay has sometimes been criticized for not involving enough students. This problem can be overcome by giving members of the audience specific aspects of the roleplay to pay attention to (Chesler, 1966). Giving the audience something to observe and report on during the follow-up discussion almost inevitably leads to more active participation. The audience can also play a more active part if the teacher selects several students from the audience to take turns playing a particular role during the activity or by having the audience invent an ending for the roleplay (Howitz, 1985). Giving the students in the audience a reason to be involved, and having them react, allows everyone to participate.

During roleplay activities, the teacher's role is to go from group to group encouraging students to participate, offering help as needed and taking note of both organizational and linguistic problems that the students may be having. When the students are actually roleplaying it is best not to interrupt unless communication breaks down completely.

Providing feedback to students is an excellent way to wrap up this type of activity. This wrap up can take the form of a discussion where students and teacher further explore the content and characters of the roleplay. The teacher might also take this opportunity to mention the strong and weak points that she took note of while the students were working in small groups. If you want to find out more about the different phases involved in a roleplay activity, you can consult Milroy's article (1982) which provides examples of what actually takes place before (briefing), during (interaction), and after (discussion) a roleplay activity.

\section{How much language control is necessary during roleplay?}

Beginning students usually need a more controlled situation because of the minimal amount of language available to them. The less control there is in a roleplay activity, the less the language is predictable. Certain language restrictions are comforting to students just beginning to learn a second or foreign language.

An important consideration is to maximize student learning by developing roleplay situations which incorporate as many elements as possible from situations students have to deal with in their own lives (Littlewood, 1975; Piper, 1983, 1984; White, 1984).

Littlewood describes roleplay activities which progress from performing memorized dialogues (controlled) to improvisation (creative). He cites examples of each and how they are to be conducted. Dobson (1974) also suggests roleplay activities which progress from tightly controlled to creative improvisation.

In reading this article, I am sure that many more questions regarding 
roleplay activities have come to mind. However, I would like to encourage you to try roleplay activities with your own students because I have always found that second language learners have benefited from participating in these activities.

\section{REFERENCES}

Chesler, M. \& Fox, R. (1966). Role-playing methods in the classroom. Chicago: Science Research Associates, Inc.

Dobson, J.M. (1974). Effective techniques for English conversation groups. Rowley, Mass.: Newbury House Publishers.

Finocchiaro, M. \& Brumfit, C. (1983). The functional-notional approach: From theory to practice. New York: Oxford University Press.

Howitz, E.K. (1985). "Getting them all into the act: Using audience participation to increase the effectiveness of roleplay activities." Foreign Language Annals, 18(3), 205-207.

Littlewood, W.T. (1975). "Role performance and language teaching." IRAL, 13(3), 199-208.

Livingstone, C. (1982). Role play. Aberdeen, G.B.: Aberdeen University Press.

Piper, D. \& Piper, T. (1983). "Reality and second language role play." Canadian Modern Language Review, 40(1), 82-87.

Piper, T. (1984). "Putting reality into role play." TESL Canada Journal, 1(2), 29-34.

van Ek, J.A. (1976). The threshold level for modern language learning in schools. London: Longman.

White, J. (1984). "Drama, communicative competence and language teaching: An overview." Canadian Modern Language Review, 40(4), 595-599.

\section{THE AUTHOR}

Suzanne Larocque is currently completing the Bachelor of Education in TESL at McGill University. She holds a BA in German and has taught ESL at primary and secondary levels. Her main areas of interest in ESL are group dynamics and communicative language testing. 